\title{
EVALUATION OF WATER FOOTPRINT OF SELECTED CROP CONSUMPTION IN TEHRAN PROVINCE
}

\author{
ReZAei Kalvani, S. ${ }^{1}$ - SharaAi, A. ${ }^{1 *}$ - MANAF, L. $^{1}-$ HAMidian, A. ${ }^{2}$ \\ ${ }^{I}$ Faculty of Environmental Studies, Universiti Putra Malaysia, 43400 UPM Serdang, Selangor, \\ Malaysia \\ ${ }^{2}$ Department of Environmental Science and Engineering, Faculty of Natural Resources, \\ University of Tehran, Karaj, Iran \\ *Corresponding author \\ e-mail: amirsharaai@upm.edu.my; phone: +60-3-8946-8031; fax: +60-3-8946-7468
}

(Received 30 ${ }^{\text {th }}$ Mar 2019; accepted $13^{\text {th }}$ Jun 2019)

\begin{abstract}
The sharp increase in water consumption poses a risk of increasing water scarcity in developing countries. The aim of this study is to the quantify variability of per capita Water Footprint (WF) of consumption of selected crops in Tehran province from 2008-2014. Blue and green WF were computed using WF approach. Besides, per capita WF of crop consumption was evaluated using bottomup approach. The result illustrated the external water footprint had the largest contribution in total WF of crops consumption in the Tehran province (2008-2014). The total water footprint of crop consumption decreased because the population and per capita WF also decreased. Besides, wheat and rice had the largest per capita WF. This study discloses that it is essential to have appropriate water management to reduce water stress originating from agricultural sector in future. The consumption of wheat in Iran is high, more precisely 2 times larger than global average. It is recommended to reduce the consumption of wheat in Tehran or replace it with other crops. Besides that, decision makers in agricultural sector should reduce water lost, with declining production of cherry, pear, and peach. Furthermore, reducing water footprint of crops and efficient agricultural water management are recommended.
\end{abstract}

Keywords: per capita water footprint, water consumption, agricultural water management, CROPWAT model, virtual water

\section{Introduction}

Water footprint is identified as a strong tool to evaluate water consumption through the supply chain of products because it has multidimensional indicator which is able to evaluate direct and indirect water consumption. Besides, water footprint contains information about the types of water used including ground and surface water footprint (blue WF) and irrigation water footprint (green WF) (Hoekstra et al., 2011). The WF method is able to evaluate water consumption in a variety of scale from city (Wu, 2014) to global scale (Hoekstra and Chapagain, 2007). Water footprint of provinces is calculated by summing up the internal and external WFs (Hoekstra and Chapagain, 2007). Virtual water trade plays an important role in mitigating water shortages in water-stressed areas (Qian et al., 2018). However, exporting crops from water-stressed regions can increase water scarcity. Iran is facing severe water scarcity due to population growth, economic growth, inefficiency of agricultural water usage, and inappropriate water management (Madani, 2014). Besides, Iran has the largest blue water consumption and blue water footprint per capita (Hoekstra and Mekonnen, 2011).

In spite of existing vast number of literature, there has been lack of attention to the annual changes of water footprint of crop consumption and the associated water loss and saving at provincial scale. Besides, most of the studies have evaluated water 
footprint at country scale (Gephart et al., 2016; Ge et al., 2011; Zhuo, Mekonnen, and Hoekstra, 2016; Feng et al., 2015). It is important to know how much water is consumed due to crop use and how human consumption pattern impacts inter-provincial and international water dependencies. Very few studies have been done on the water footprint of Iran's crop consumption (Hoekstra and Mekonnen, 2011; Hoekstra and Chapagain, 2007; Karandish and Hoekstra, 2017); on water footprint of cereal crops throughout different provinces in Iran (Ababaei and Etedali, 2016); on water footprint of the cement industry in western Iran (Hosseinian and Nezamoleslami, 2018) and on the virtual water trade in Iran (Yousefi et al., 2017; Faramarzi et al., 2010). Besides, there has been lack of attention on the provincial water footprint and water saving assessment. Okadera et al. (2015) applied the "top-down" approach to evaluate the WF of energy supplies in one of China's provinces. Besides that, Zhao et al. (2018) and Chen et al. (2017) have assessed water footprints in all the provinces of China.

The objective of this research is to evaluate and analyze water footprint of 14 important crops in Tehran province and to assess water savings and losses from 2007 to 2014.

\section{Materials and methods}

\section{Area of study}

Tehran province is located in the northern central plateau of Iran with population of more than 13 million people in 2014. It accommodates approximately $18 \%$ of Iran population (Statistical Centre of Iran). It is the richest province in Iran which contributes approximately $29 \%$ of overall GDP. The area of Tehran province spans $18,909 \mathrm{~km}^{2}$. The climate in the northern part of Tehran is alpine whereas in the southern part, it is arid and semi-arid. The total average rainfall is around $200 \mathrm{~mm}$ annually. The sum of precipitation with minimum and maximum temperature in Tehran in 2008 is illustrated in Figure 1.

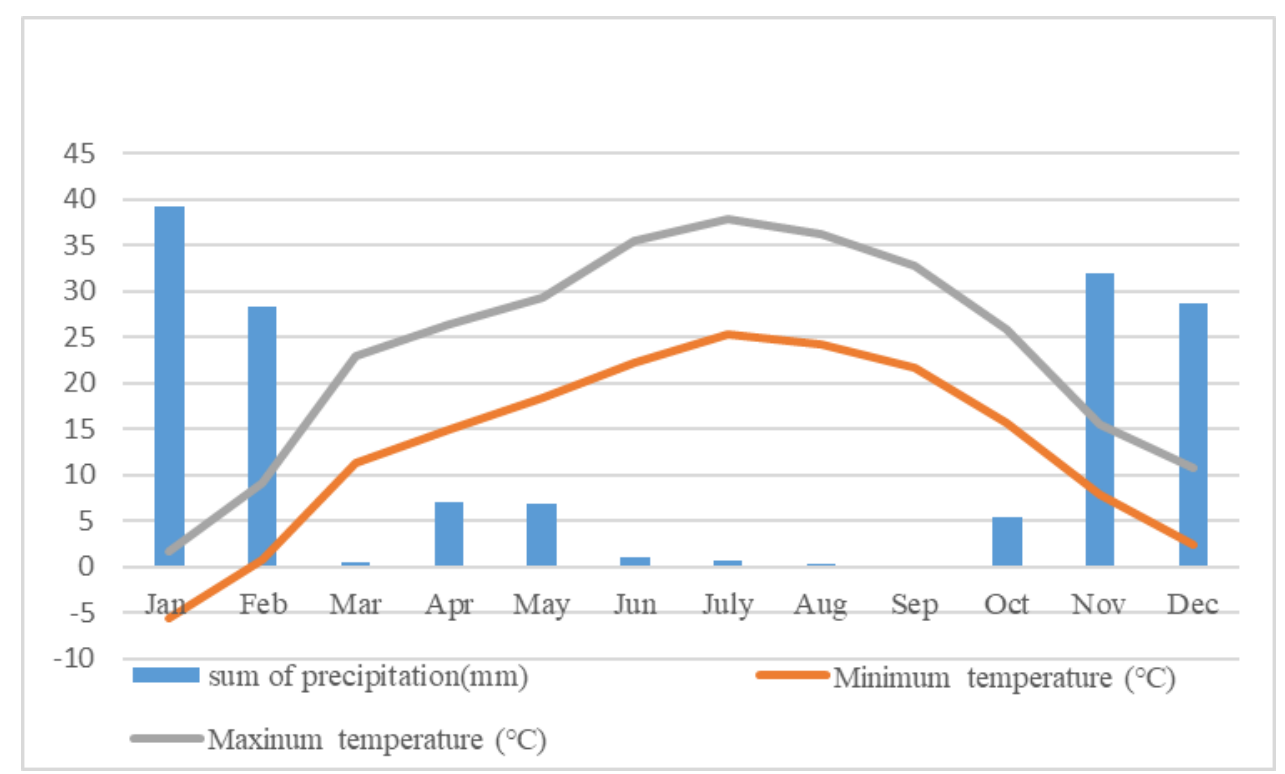

Figure 1. The plot of minimum and maximum temperature and sum of precipitation (2008) 
The nation water footprint has two components: internal and external. Internal WF is the water footprint of crops that are produced within the border of Tehran for domestic consumption. On the other hand, external WF refers to WF of crops produced outside of (imported to) Tehran and consumed within Tehran. The WF in Tehran province is evaluated by summing up internal and external WF (Fig. 2). Besides, it is important to distinguish between WF of production and WF of consumption. WF of production is defined as the volume of WF that is used from domestic water resources for production of goods and services. However, consumptive WF refers to the volume of WF that is used from domestic and foreign water resources for domestic consumption (Hoekstra and Mekonnen, 2011).

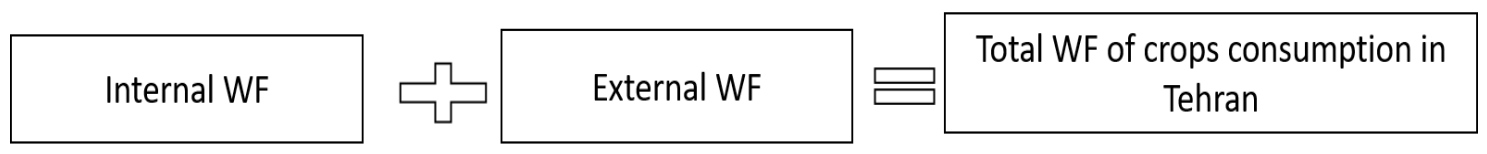

Figure 2. National water footprint accounting framework based on Hoektra method (Hoekstra and Chapagain, 2007)

First of all, the water footprint of crop production in Tehran province was evaluated. It was calculated based on Hoekstra method (Hoekstra et al., 2011). Secondly, WF of crops that are produced outside Tehran and consumed within Tehran (Hamedan, Lorestan, Ahvaz, Mazandaran, Qazvin, and Kermanshah provinces); also known as external WF was evaluated. Finally, per capita WF of crops, water saving, and water loss in Tehran were assessed.

\section{Internal and external water footprint of crops in Tehran province}

The WF of cultivated crops in Tehran, as well as imported crops from other provinces to Tehran were evaluated. For this research, the most important crops were selected including wheat, barley, maize, peaches, potatoes, rice, onions, tomatoes, grapes, oranges, cherries, peas, and apples. Water footprints of these crops were computed based on Hoekstra approach. The CROPWAT software was used to compute evapotranspiration of each growing crop.

\section{Water footprint assessment methodology}

The blue and green WF for each crop and each year were evaluated for each province based on Hoekstra approach. The blue WF was calculated by dividing blue Crop Water Use CWU blue $\left(\mathrm{m}^{3} / \mathrm{ha}\right.$ ) by the yield (Y) (ton/ha) - Equation 1 (Hoekstra et al., 2011). The green water footprint was computed using similar method - Equation 2 (Hoekstra et al., 2011).

$$
\begin{gathered}
W F_{\text {blue }}=\frac{C W U_{\text {blue }}}{Y} \\
W F_{\text {green }}=\frac{C W U_{\text {green }}}{Y}
\end{gathered}
$$


Crop water use (CWU blue and CWU green) were derived by multiplying 10 with ET blue

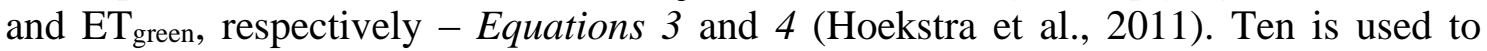
convert the unit of millimetre, $\mathrm{mm}$ to $\mathrm{m}^{3}$.

$$
\begin{gathered}
C W U_{\text {blue }}=10 \sum_{d}^{\lg p} E T_{\text {blue }} \\
C W U_{\text {green }}=10 \sum_{d}^{\lg p} E T_{\text {green }}
\end{gathered}
$$

Measurement of ET is laborious and time-consuming, hence CROPWAT model was used to simulate ET for each crop by using climate data and crop parameters based on Allen method (Allen, 1998).

\section{Water footprint of crop consumption}

The blue and green WF of each crop were evaluated $\left(\mathrm{m}^{3} / y e a r\right)$ using bottom-up method (Hoekstra et al., 2011). The water footprint for each crop was estimated by multiplying the volume of crop consumption by water footprint of crops. The WF of crops was calculated using Equation 5.

$$
W F_{\text {cons,indir }}=\sum_{p}^{n}\left(c[p] \times W F_{P[P]}\right)
$$

where $\mathrm{C}\lceil\mathrm{P}\rceil$ refers to the volume of crop consumption of product $\mathrm{p}$ within Tehran (ton/year) and $W F_{\text {pro[p] }}$ is WF of crop production from originating region ( $\left.\mathrm{m}^{3} / \mathrm{ton}\right)$.

\section{Water saving and loss}

Water saving through international crop trade was evaluated based on Champaign et al. method (2006). It was calculated by multiplying the volume of import of crops $\left(\right.$ ton $\left.\mathrm{y}^{-1}\right)$ by the WF of the crops $\left(\mathrm{m}^{3}\right.$ year $\left.{ }^{-1}\right)$ within Tehran. The inter-provincial water saving through inter-provincial trades was assessed using similar method. The water footprints of imported crops from abroad were obtained from Mekommen and Hoekstra (2011). The blue and green water losses were accounted as the water footprints of extra production exported to other regions.

\section{Data}

The volume of crop yield and crop production in Tehran and other provinces were obtained from the Ministry of Agriculture, Jahad, in Tehran. The climate data including minimum and maximum temperature, rainfall, sunshine, humidity, and wind speed were obtained from Mehrabad weather station. Rooting depth, critical depletion, yield response, crop height is obtained from OPTIWAT which were local data. Data for the volume of crop consumption and trade were obtained from Tehran's chambers of commerce, industries, mines and agriculture. 


\section{Results}

Per capita (green and blue) WF of different crop consumption is shown in Figure 3. The per capita water footprint of wheat in 2010 had increased due to the increase in the volume of production within the Tehran province which held large volume of WF as compared to the external WF. Besides, WF of wheat consumption showed reduction trend due to the decrease of per capita wheat consumption. WF of rice consumption showed fluctuating trend as it depends on the volume of consumption which was fluctuating too. Besides that, rice consumption per person had decreased from $35 \mathrm{~kg} / \mathrm{cap}$ in 2008 to $34 \mathrm{~kg} / \mathrm{cap}$ in 2014.

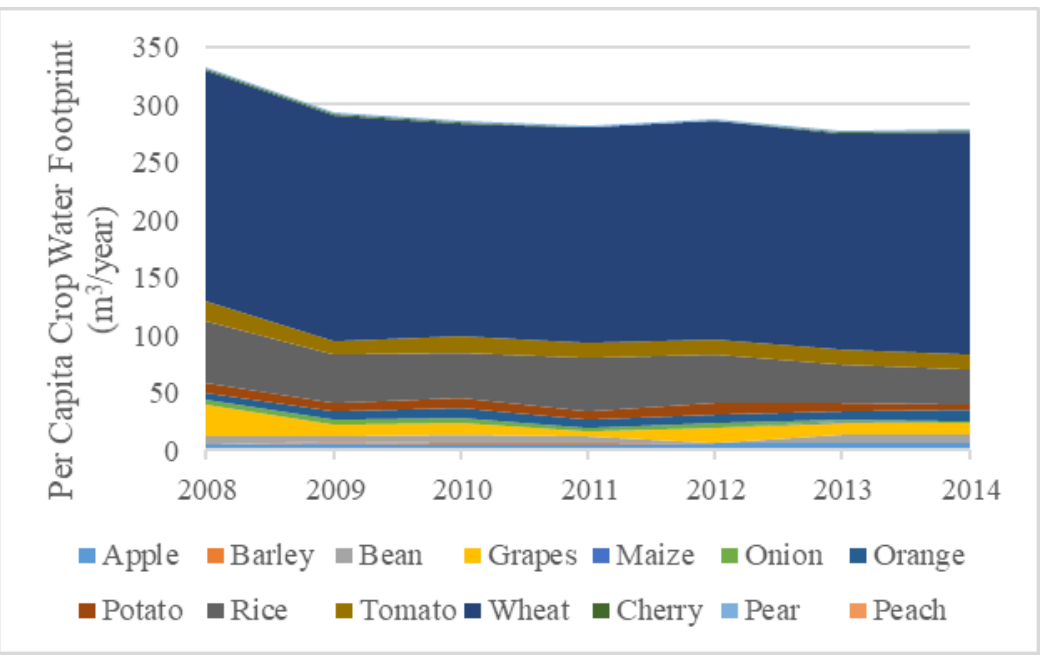

Figure 3. Per capita water footprint of crop consumption (2008-2014)

Figure 4 illustrates the total WF of crop consumption in Tehran province (20082014). It shows a declining trend in 2010 due to the decrease in the population of Tehran ever since Alborz province was separated from Tehran during the same year. Besides that, the per capita consumption of wheat and rice had also decreased.

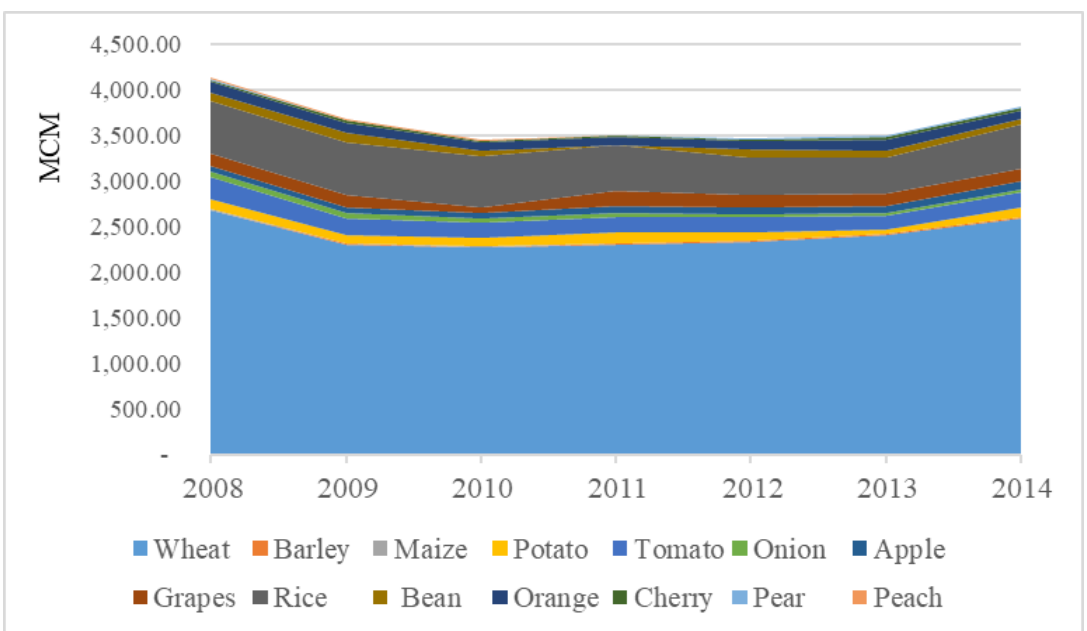

Figure 4. The total WF of crop consumption in Tehran province (2008-2014) 
Figure 5 shows the internal and external WF of different crops in the Tehran province. Tehran province is independent of external WF in the production of apples, pears, peaches, and cherries. This means, Tehran province produced and consumed all of the produce. Besides, Tehran imported 2,848 billion $\mathrm{m}^{3}$ of virtual water and consumed 377 million $\mathrm{m}^{3}$ of internal water footprint in 2008. Tehran saved water resources by importing crops from other provinces and abroad. For example, most of the wheat consumption within Tehran is imported from the USA. Wheat and rice have the largest WF of consumption in Tehran province since both of them are consumed at a large scale.

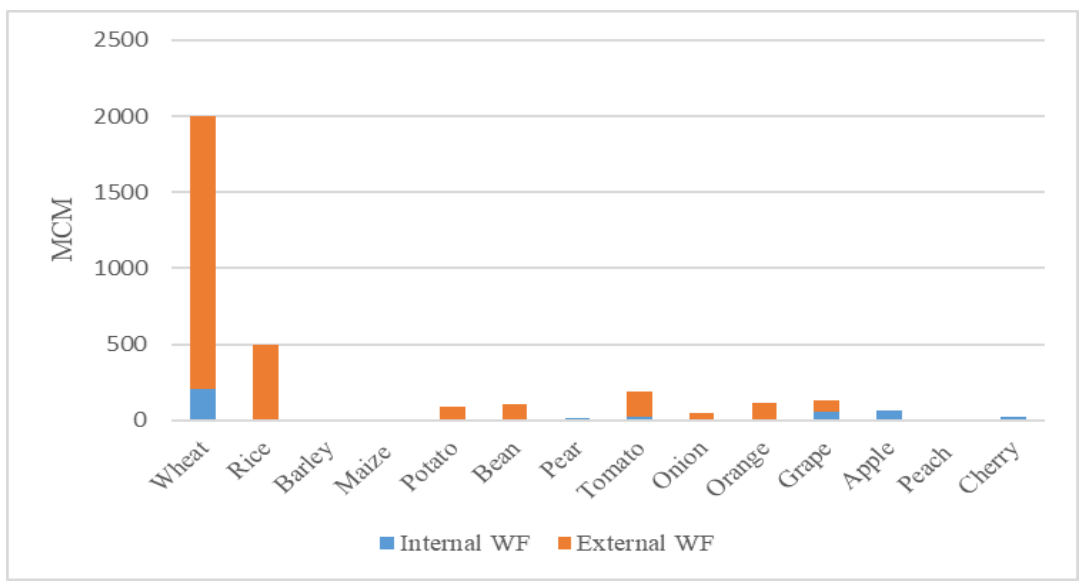

Figure 5. Internal and external WF of crop consumption in Tehran province

Figure 6 shows the average per capita WF of crop consumption in Tehran province. Wheat had the largest per capita WF (blue and green) amounting to $189 \mathrm{~m}^{3} / \mathrm{cap} /$ year from 2008 to 2014. Next to wheat, rice had the largest per capita WF amounting to $46 \mathrm{~m}^{3} /$ cap/year. These were followed by tomatoes, potatoes, oranges, beans, apples, and grapes respectively. Cherries, pears, barley, peaches, and maize had low per capita WF.

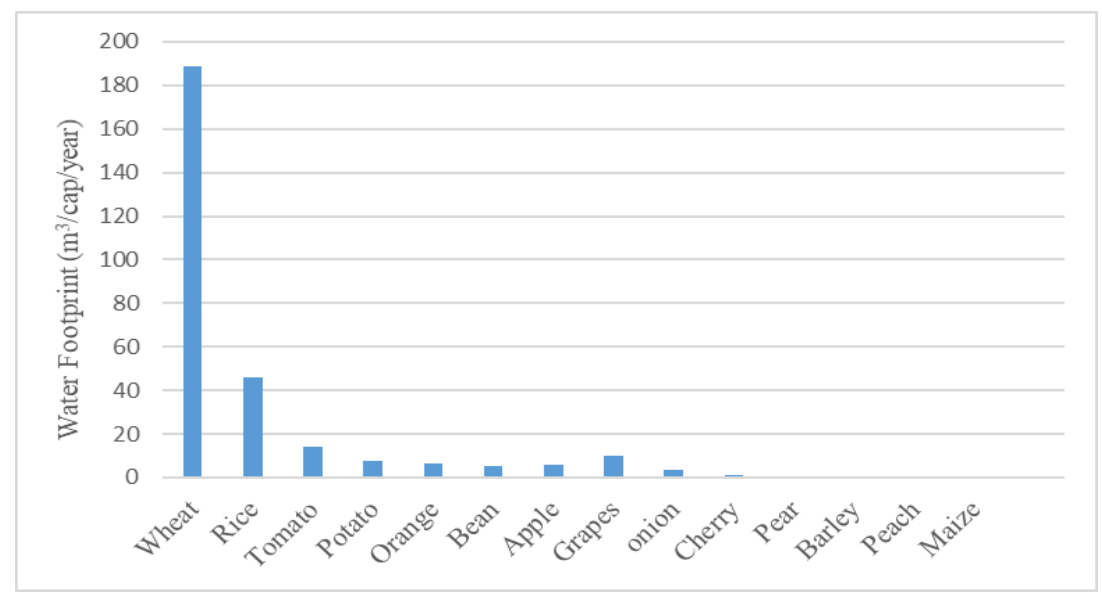

Figure 6. The average per capita WF of different crops (2008-2014) 
Internal and external water footprint trend (2008-2014) is illustrated in Figure 7. Dependency on external WF had increased in 2010 when Alborz had separated from Tehran. Internal water footprint was a bit higher in 2014 which means water footprint in 2014 had increased. The external water footprint in 2014 was higher than 2008 because consumption of wheat had decreased.

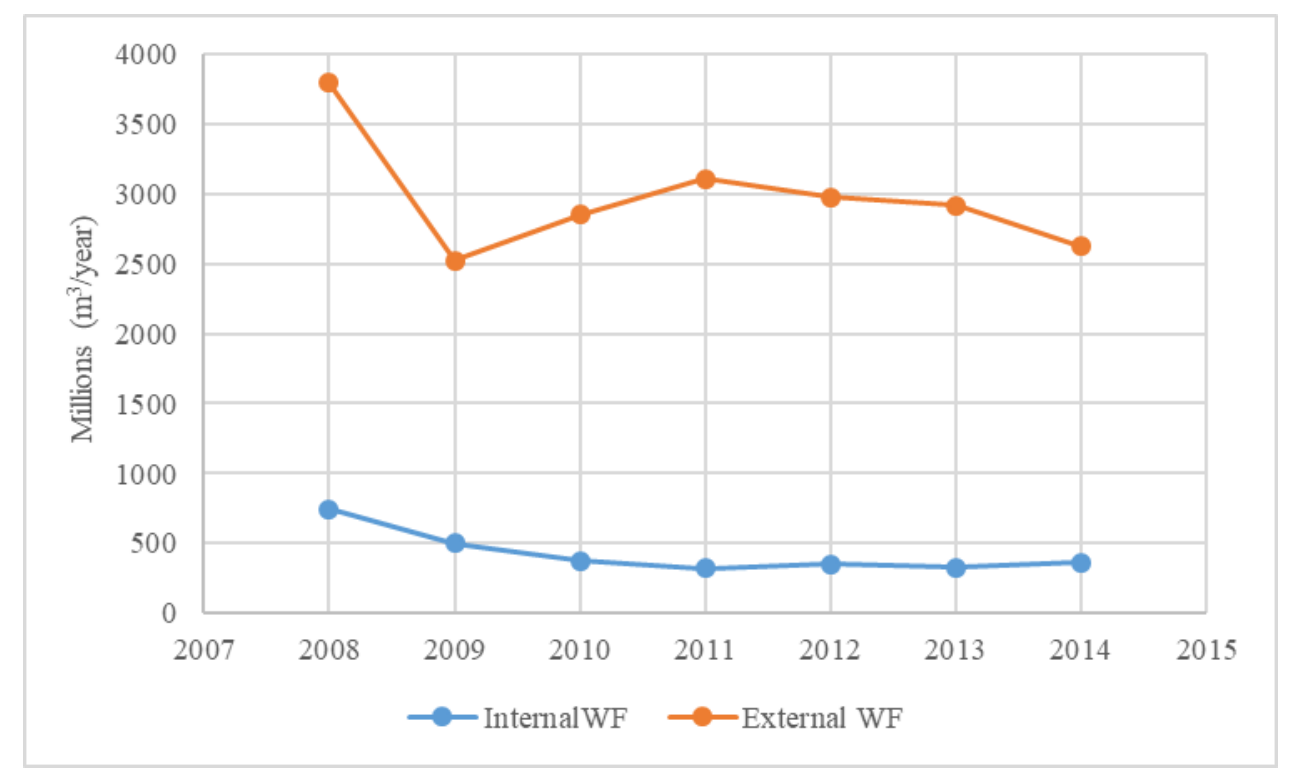

Figure 7. The internal and external WF trend (2008-2014)

Figure 8 shows the proportion of internal and external WF in Tehran province. Only $10 \%$ of Tehran's WF is attributed to internal WF. Most of the crops are produced outside of Tehran and exported into the Tehran province.

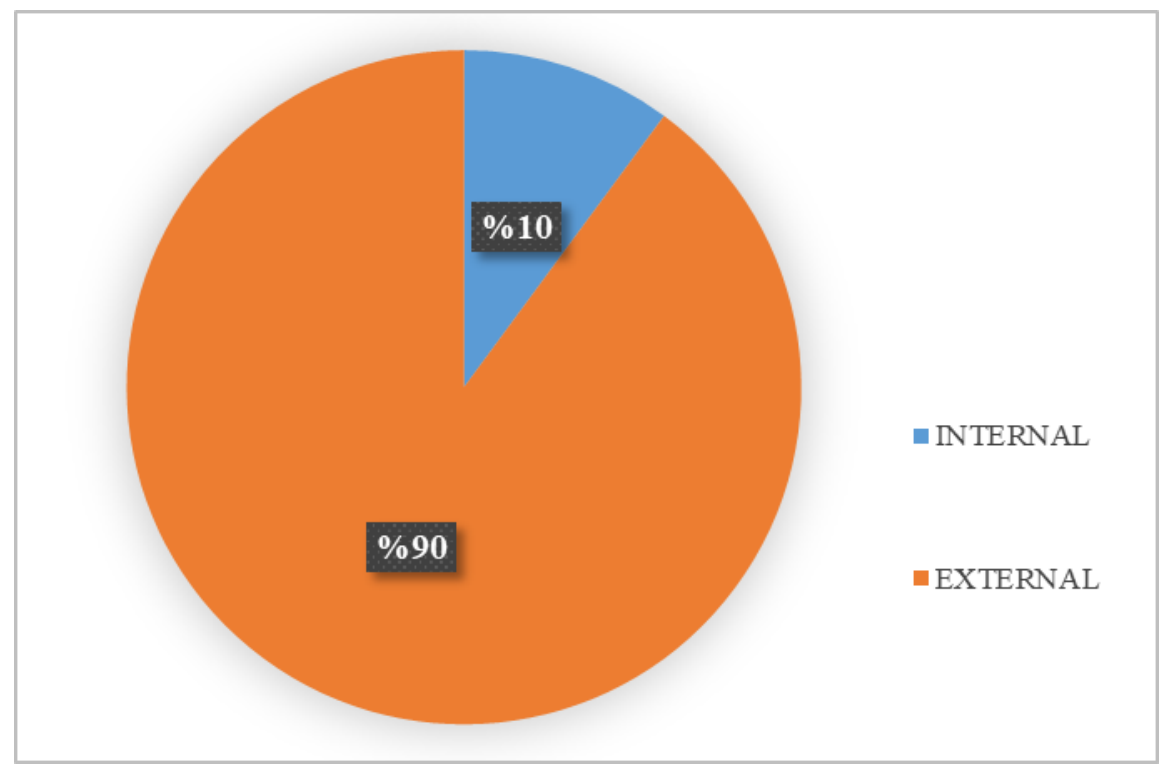

Figure 8. The contribution of internal and external WF in Tehran's total WF 
Figure 9 shows the total water footprint of Tehran province in agricultural sector for selected crops; derived by summing up the internal and external WF. The internal and external WF amounted to $377 \mathrm{million}^{3} /$ year, and 2,848 billion $\mathrm{m}^{3} /$ year respectively. The total water consumption was 3,225 billion $\mathrm{m}^{3} / \mathrm{year}$. Blue WF accounted for the largest contribution of internal WF while green WF was the largest shareholder of external WF. By importing crops externally, there will be more saving for Tehran's blue WF.

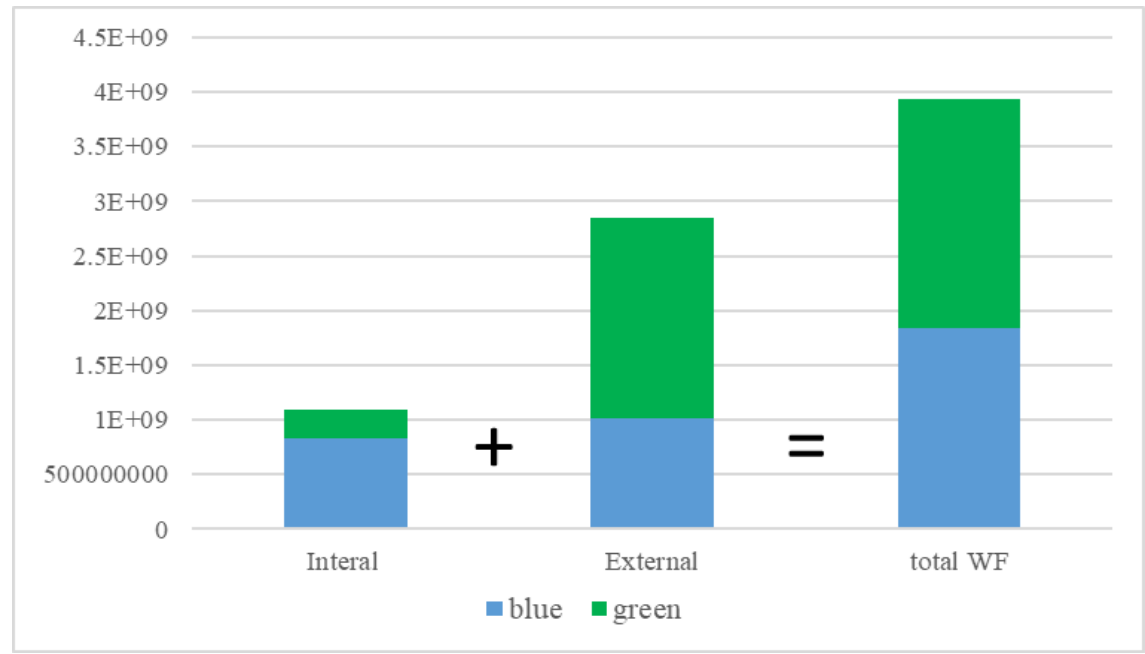

Figure 9. The total WF in Tehran province

Figure 10 shows the total blue and green water savings (WS) as a result of international and inter-provincial trades which have fluctuations. The blue water saving resulting from international trade had increased from 1.79 billion $\mathrm{m}^{3}$ in 2010 to 1.9 billion in 2014 due to the increase in dependency on external WF. The total blue water saving from both international and inter-provincial crops had increased from 3,161 billion in 2008 to 3,234 billion $\mathrm{m}^{3}$ in 2014 .

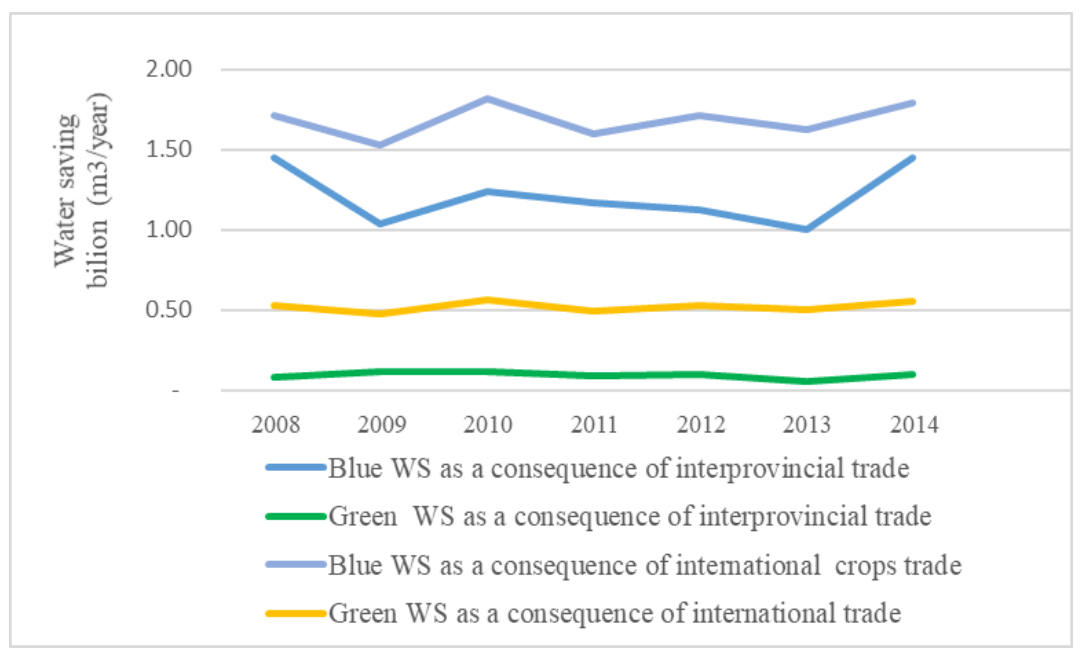

Figure 10. Blue and green water saving as a result of international and inter provincial trade in Tehran (2008-2014) 
Blue WF per ton of crops in exporting countries are lower than Tehran as it has arid climate with high evapotranspiration. Blue water saving is increased as a result of international trade. On the other hand, green water saving is low because crop production within Tehran is mostly related to blue water footprint. Besides, green water footprint within the exporting region for all crops is larger than Tehran. Moreover, interprovincial and international crop trades contribute to overall blue water saving.

Table 1 illustrates water savings from both international and national crop trades in 2008 and 2014. It shows that WS for wheat, potatoes, and onions in 2008 is lower than 2014 as the production of these crops within Tehran had increased. While WS for rice had decreased due to decline in the volume of rice consumption in 2014.

Table 1. The water saving as a result of crops trade in Tehran Province (2008 and 2014)

\begin{tabular}{c|c|c}
\hline & WS as a result of crops trade $\left(\mathbf{m}^{3} /\right.$ year $)$ & WS as a result of crops trade $\left(\mathbf{m}^{\mathbf{3}} /\right.$ year $)$ \\
\cline { 2 - 3 } & $\mathbf{2 0 0 8}$ & $\mathbf{2 0 1 4}$ \\
\hline Wheat & $2,237,927,587.50$ & $2,343,328,030$ \\
Rice & $1,111,524,117$ & $993,982,416$ \\
Potato & $83,311,520$ & $103,726,320$ \\
Tomato & $108,496,382$ & $91,565,460$ \\
Onion & $8,120,862$ & 9927648 \\
Grapes & $219,463,024$ & $147,818,440$ \\
\hline
\end{tabular}

\section{Blue and green water losses in Tehran}

Fig. 11 shows total blue water loss in Tehran province from 2008 to 2014. The total blue water loss had declined from 100 million $\mathrm{m}^{3}$ in 2008 to 28 million $\mathrm{m}^{3}$ in 2009 due to the reduction in production amount. Total green water loss had also decreased from 9 million $\mathrm{m}^{3}$ in 2008 to 4 million $\mathrm{m}^{3}$ in 2009. Moreover, Alborz province had been separated from Tehran during this time and most of the extra production came from pears and peaches of this province (2008). Then, blue water loss showed a fluctuating trend from 2009 to 2014 as it relies on the volume of extra production and the blue WF amount which are not stable. Blue water loss was larger than green water loss as the production of crops in Tehran relies on blue WF.

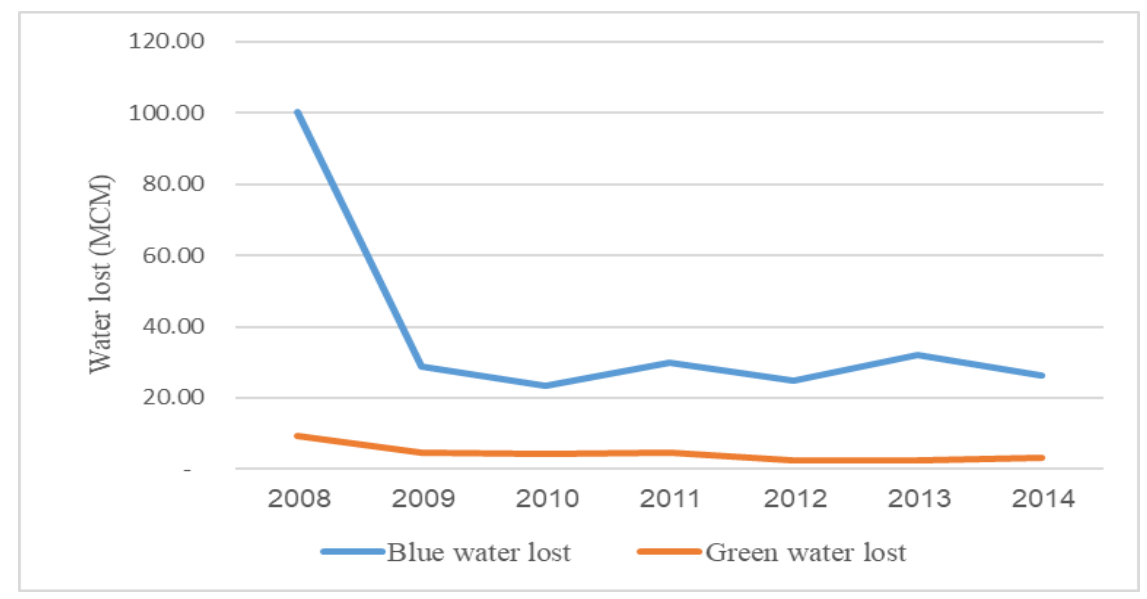

Figure 11. The blue and green water lost (2008-2014) 


\section{Discussion}

Water footprint accounts for the volume of actual water consumption by humans. It is identified as an appropriate indicator for computing the impact of human activities on water resources. According to current research, there are four major factors impacting water footprint of crop consumption: (1) Population, (2) the volume of crop consumption, (3) the volume of internal production, (4) the external WF per ton of crop production. Besides that, water footprint of crop consumption in Tehran showed a reduction trend due to the increase in external WF. In the current study, per capita WF for wheat in Tehran was larger than evaluated by Hoekstra who has evaluated per capita WF at global scale. However, our result is different because this assessment is done at local scale. Besides, most of the wheat consumed in Tehran are imported from the USA which has low WF. Additionally, other studies have evaluated that water footprint of cereal crops in arid region of Iran was $397 \mathrm{~m}^{3} /$ capita/year which are relatively similar to our result (Karandish and Hoekstra, 2017).

The result indicates that crop production in Tehran has the largest WF compared to other countries, similar to Hoekstra's result who claims that water footprint of Iran is high due to low productivity and high evapotranspiration (Hoekstra and Chapagain, 2007; Fader et al., 2011).

The WF of crop consumption shows a reduction trend which disagrees with the result of Karandish who claims that WF of crop consumption for all provinces of Iran has increased because of population growth and increase in crop consumption (Karandish and Hoekstra, 2017). The WF consumption had decreased from 2008 to 2014 in Tehran province due to the increase in dependency on external WF and decrease in population. The reason for population decrease was Alborz separation from Tehran province in 2010.

\section{Conclusion}

This study shows Tehran's water self-sufficiency had decreased from 2008 to 2014. Furthermore, per capita WF of crop consumption had decreased due to the increase in dependency on external WF and decrease in population from 2008 to 2014 . WF per ton of imported crop production was lower than Tehran because of climate condition. Besides, WF of crop consumption within Tehran is more strongly reliant on external WF. Tehran province has produced only 10 per cent of its crop consumption; it has been under severe water scarcity due to population and climate condition. Moreover, Tehran province can save water resources by importing crops from water-abundant areas. Tehran saved 3.23 billion $\mathrm{m}^{3}$ of internal water resources through inter-provincial and international crop trade in 2014.

Total blue and green water losses had decreased from 2008 to 2014 due to reduction in the volume of extra production when Alborz was separated from Tehran province. Water loss depends on extra production that is exported to other regions. The decision makers should reduce the production of fruits for export purposes such as pears, peaches, and cherries because Tehran is under high groundwater stress with moderate surface water scarcity (Rezaei Kalvani et al., 2019). Additionally, production of cereal crops should be reduced as these crops consume high volume of blue water in Tehran due to climate condition.

Water footprint assessment can contribute to enhance water use efficiency in agricultural sector by providing useful information for decision makers. Besides, it is 
crucial to apply developed technology and appropriate water management in order to enhance water use efficiency and lower water footprint per ton of crops to reduce per capita water footprint in Tehran.

The consumption of wheat in Iran is high; two times higher than global average. Change in food consumption habits contributes to increased food security at regional scale. It is recommended to reduce the consumption of wheat in Tehran or replace it with other crops. Besides, changing food consumption habits contributes to increase food security at a regional scale. It would also be helpful to assess the per capita water footprint of different dietary changes in the future water footprint assessment.

Acknowledgements. The authors would like to gratefully acknowledge Universiti Putra Malaysia (GP/2018/9592300) for supporting this research project.

\section{REFERENCES}

[1] Ababaei, B., Etedali, H. R. (2017): Water footprint assessment of main cereals In Iran. Agricultural Water Management 179: 401-411.

[2] Allen, R. G. et al. (1998): Crop Evaporation Guideline for Computing Crop Water Requirements. - FAO Irrigation and Drainage Paper 56, FAO, Rome.

[3] Chen, W. et al. (2017): China's water footprint by province, and inter-provincial transfer of virtual water. - Ecological Indicators 74: 321-333.

[4] Fader, M. et al. (2011): Internal and external green-blue agricultural water footprints of nations, and related water and land savings through trade. - 1641-1660.

[5] Faramarzi, M. et al. (2010): Analysis of intra-country virtual water trade strategy to alleviate water scarcity in Iran. - Hydrology \& Earth System Sciences Discussions 7(2): 1417-1433.

[6] Feng, L. et al. (2015): The driving force of water footprint under the rapid urbanization process: a structural decomposition analysis for Zhangye City in China. - Journal of Cleaner Production 163: S322-S328.

[7] Ge, L. et al. (2011): An Evaluation of China's Water Footprint. - Water Resources Management 25(10): 2633-2647.

[8] Gephart, J. A. et al. (2016): The environmental cost of subsistence: optimizing diets to minimize footprints. - Science of the Total Environment 553: 120-127.

[9] Hoekstra, A. Y. et al. (2011): The Water Footprint Assessment Manual. Setting the Global Standard. - Earthscan, London.

[10] Hoekstra, A. Y., Chapagain, A. K. (2007): Water footprints of nations: water use by people as a function of their consumption pattern. - Water Resources Management 21(1): $35-48$.

[11] Hoekstra, A. Y., Mekonnen, M. M. (2011): The water footprint of humanity. Proceedings of the National Academy of Sciences 109(9): 3232-3237.

[12] Hosseinian, S. M. and Nezamoleslami, R. (2018): Water footprint and virtual water assessment in cement industry : a case study in Iran. - Journal of Cleaner Production 172: 2454-2463.

[13] Karandish, F., Hoekstra, A. Y. (2017): Informing national food and water security policy through water footprint assessment : the case of Iran. - Water 9(11): 831.

[14] Madani, K. (2014): Water management in Iran: what is causing the looming crisis? Journal of Environmental Studies and Sciences 4: 315-328.

[15] Okadera, T. et al. (2015): Evaluating the water footprint of the energy supply of Liaoning Province, China: a regional input-output analysis approach. - Energy Policy 78: 148-157. 
[16] Qian, Y. et al. (2018): Water footprint characteristic of less developed water-rich regions: Case of Yunnan, China. - Water Research 141: 208-216.

[17] Rezaei Kalvani, S. et al. (2019): Assessing ground and surface water scarcity indices using ground and surface water footprints in the Tehran province of Iran. - Applied Ecology and Environmental Research 17(2): 4985-4997.

[18] Wu, L. (2014): Analysis of water sustainable utilization in Changsha city based on water footprint theory. - Applied Mechanics and Materials 694: 532-535.

[19] Yousefi, H. et al. (2017): Virtual water evaluation for grains products in Iran. Case study: pea and bean. - Journal of Water and Land Development 35(1): 275- 280.

[20] Zhao, G. et al. (2018): Provincial water footprint in China and its critical path. Ecological Indicators 105: 634-644.

[21] Zhuo, L., Mekonnen, M. M., Hoekstra, A. Y. (2016): Consumptive water footprint and virtual water trade scenarios for China - with a focus on crop production, consumption and trade. - Environment International 94: 211-223. 